\section{Asphyxia while swallowing solid food caused by bronchial compression: a variant of the pneumonectomy syndrome}

\author{
K M Fong, K D McNeil, K P Kennedy, \\ K S Matar, P H Cole, J B Partridge
}

\begin{abstract}
A 40 year old man presented with recurrent episodes of dyspnoea whilst swallowing solid food. He had undergone right pneumonectomy and thoracoplasty for recurrent pneumonias and empyema 23 years previously. Solid food boluses appeared to cause bronchial obstruction by compressing the surgically distorted left main bronchus. This is a new variant of the post pneumonectomy syndrome.
\end{abstract}

(Thorax 1994;49:382-383)

The postpneumonectomy syndrome is an uncommon delayed complication of pneumonectomy, usually right sided pneumonectomy, occurring in children and adults. ${ }^{1-5}$ After right pneumonectomy, extreme mediastinal shift and distortion can cause compression of the distal trachea and left main bronchus between the aorta and pulmonary artery, leading to dyspnoea and recurrent infections. ${ }^{1}$

\section{Case report}

A man aged 17 underwent right pneumonectomy because of recurrent pneumonias complicating congenital cystic bronchiectasis and bronchomalacia. Limited thoracoplasty with partial resection of the third, fourth and fifth ribs was subsequently required for postoperative empyema.

At the age of 18 complaints of breathlessness during the swallowing of solid food were thought to be functional as the chest radiograph and barium swallow appeared to be consistent with the usual postoperative appearances. His symptoms gradually progressed until a severe episode resulted in a near respiratory arrest at the age of $\mathbf{4 0}$ leading to hospital admission.

Physical examination revealed considerable chest wall deformity and absent right sided breath sounds. His FEV 1 was 1.61 (predicted 2.661 ), vital capacity 1.861 (3.921). Arterial $\mathrm{PO}_{2}$ was $13.2 \mathrm{kPa}$ and $\mathrm{PCO}_{2}$ was $5.6 \mathrm{kPa}$ on room air. The chest radiograph showed mediastinal displacement to the right and thoracoplastic chest wall deformity (fig 1). No

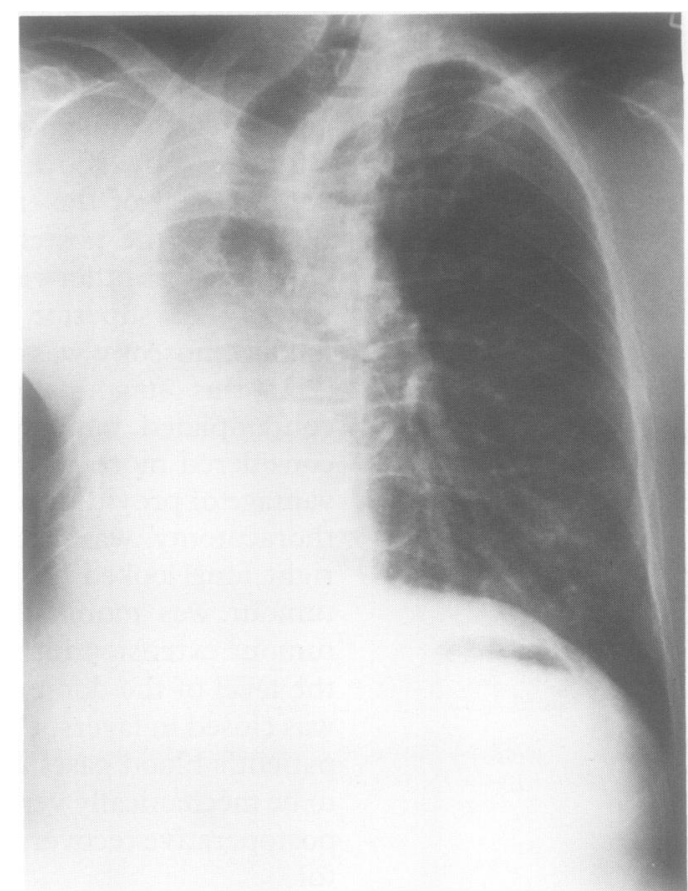

Figure 1 Postero-anterior chest radiograph showing the chest wall deformity and gross mediastinal displacement.

obvious tracheobronchial malacia was seen on fibreoptic bronchoscopy or fluoroscopic imaging. Oesophagogastroscopic findings were normal. Liquid barium cine swallow showed deviation and some dilataton of the thoracic oesophagus and peristaltic waves were irregular and of poor quality in the distal oesophagus. Computed tomographic scanning showed gross rightward mediastinal shift, counter clockwise rotation of heart and great vessels, and left lung herniation to the right. The left main bronchus was stretched across the vertebral column, bounded by the oesophagus posteriorly and the left pulmonary artery anteriorly (fig 2). A dynamic swallowing study with barium-soaked bread showed delay of the food bolus at the level of the left main bronchus. There was no evidence of intraoesophageal air accumulation from aerophagia as a further contributory factor to bronchial obstruction.

Shortly after swallowing a piece of bread the patient complained of choking, then developed severe dyspnoea, cyanosis and ultimately unconsciousness, witnessed by two of the authors. Despite large respiratory efforts, breath sounds to the left lung were significantly reduced. His arterial $\mathrm{Po}_{2}$ of $3.5 \mathrm{kPa}, \mathrm{PCO}_{2}$ of $11.6 \mathrm{kPa}$, and $\mathrm{pH} 7 \cdot 18$ on room air confirmed respiratory failure. He recovered after vomiting the food bolus. The absence of coughing and lack of propulsive expectoration of the food bolus made the possibility of food aspiration unlikely.

\section{Discussion}

The postpneumonectomy syndrome may be a result of mechanical compression of the left main bronchus caused by the gross anatomical displacement and possibly worsened by tracheobronchial malacia. ${ }^{4}$ The symptoms are usually recurrent infections and dyspnoea, al- 


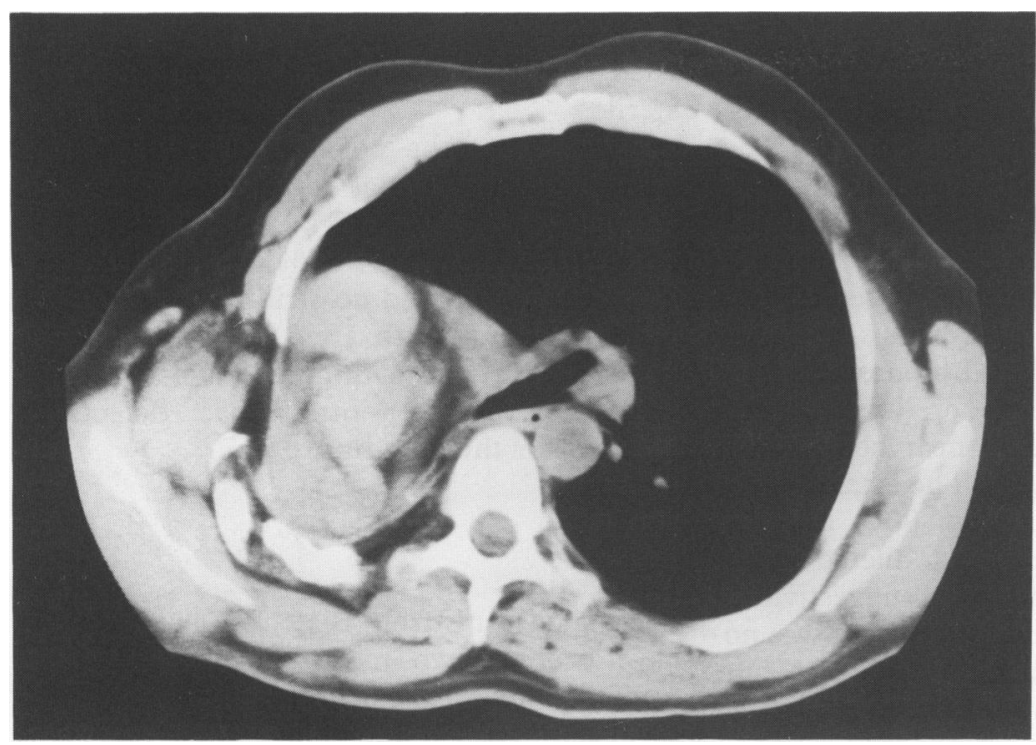

Figure 2 Computed thoracic tomogram showing the proximity and relation of the left main brochus to the vertebral column, oesophagus, and pulmonary artery.

though loss of lung function and stridor have been described. ${ }^{14}$ The diagnosis and management of this syndrome have been comprehensively discussed in a recent report. ${ }^{5}$

We report a new variant of this syndrome namely, bronchial obstruction resulting from swallowing solid food. We believe that oesophageal dilatation from a solid food bolus compressed the left main bronchus which was encased within a fixed space formed by the vertebral column, aortic arch, and great vessels. This variant probably results from an additional thoracoplastic chest wall deformity causing more than the usual postpneumonectomy anatomical derangement. In this patient a small dilatation of the poorly motile postpneumonectomy lower oesophagus from a solid food bolus appeared to cause significant left main bronchus compression.

His treatment has consisted of an exclusion diet. Whilst mediastinal repositioning and intrathoracic placement of mammary prostheses can correct the anatomical displacement in the postpneumonectomy syndrome, ${ }^{5-7}$ it was judged too hazardous in this patient because of his previous thoracoplasty and pleural infections. Pleural adhesions may cause a failure of corrective thoracotomy in the postpneumonectomy syndrome. ${ }^{4}$ Bronchial stenting of any type was considered too hazardous in this patient as any stent malfunction or problem with positioning would almost certainly have resulted in immediate death.

1 Shepard JO, Grillo HC, McCloud TC, Dedrick CG, Spizarny DL. Right pneumonectomy syndrome: radiologi findings and CT correlation. Radiology 1986;161:661-4.

2 Quillin SP, Shackleford GD. Post-pneumonectomy syndrome after left lung resection. Radiology 1991;179:100-2.

3 Wasserman $\mathrm{K}$, Jamplis RW, Lash $\mathrm{H}$, Brown HV, Cleary MG, Lafair J. Post-pneumonectomy syndrome. Chest 1979;75:78-81.

4 Whyte KF, McMahon G, Wightman AJA, Cameron EW. Bronchial compression as a result of lung herniation after pneumonectomy. Thorax 1991;46:855-7.

5 Grillo HC, Shepard JO, Mathisen DJ, Kanarek DJ. Postpneumonectomy syndrome: diagnosis, management and results. Ann Thorac Surg 1992;54:638-51.

6 Westerman CJJ, Janssen JP. Bronchial compression as a result of lung herniation after pneumonectomy (letter) Thorax 1992;47:207.

7 Jansen JP, Brutel de la Riviere A, Carpentier Alting MP, Westermann CJJ, Bergstein PGM, Duurkens VAM. Postpneumonectomy syndrome in adulthood. Chest 1992;101:1167-70.
Department of Cardiothoracic

Surgery

J Valliattu

P Jairaj

T Delamie

\section{Department of \\ Cardiology}

R Subramanyam

Department of Child

Health

$S$ Menon

$\mathrm{H}$ Vyas

Royal Hospital, Seeb, Muscat, Sultanate of Oman

Reprint requests to: Dr S Menon, Paediatric Intensive Care Unit, Roya Hospital, PO Box 1331, Hospital, PO Box 1331, Muscat, Sultanate of Oman.

Received 19 November 1992 Returned to authors 28 January 1993 Revised version received 26 April 1993 Accepted for publication 10 May 1993

\section{False aneurysm following modified Blalock-Taussig shunt}

\author{
J Valliattu, P Jairaj, T Delamie, \\ R Subramanyam, $\mathrm{S}$ Menon, $\mathrm{H}$ Vyas
}

\begin{abstract}
A nine month old infant with life threatening tracheal compression due to a Blalock-Taussig shunt aneurysm is described. Successful surgical management is discussed.
\end{abstract}

\section{(Thorax 1994;49:383-384)}

The Blalock-Taussig shunt is now a well recognised procedure for treating cyanotic congenital heart disease in infancy. The ori- ginal operation consisted of anastomosis of the subclavian artery to the pulmonary artery, ${ }^{1}$ but the use of polytetrafluoroethylene grafts to produce a communication between systemic and pulmonary circulation has simplified the procedure. ${ }^{2}$ False aneurysm formation following a modified Blalock-Taussig shunt is a rare and potentially fatal complication. ${ }^{3-5} \mathrm{We}$ report a false aneurysm presenting with tracheal compression in a nine month infant with tetralogy of Fallot who had undergone a modified Blalock-Taussig shunt in the neonatal period. The aneurysm was successfully repaired with complete relief of the tracheal compression.

\section{Case report}

Shortly after normal full term delivery a female infant was noted to be cyanosed. Echocardiographic evaluation revealed a normal visceroatrial arrangement (situs solitus), a large atrial septal defect, and a large inlet ventricular septal defect with an overriding aorta. In addition, the baby had infundibular and valvar pulmonary stenosis. The aortic arch 